\title{
Beer foam decay: effect of glass surface quality and $\mathrm{CO}_{2}$ content
}

\author{
Radek Šulc ${ }^{1, *}$, and Jiři Bojas ${ }^{1}$ \\ ${ }^{1}$ Czech Technical University in Prague, Faculty of Mechanical Engineering, Department of Process Engineering, Technická 4, 16607 \\ Prague, Czech Republic
}

\begin{abstract}
The effect of beer glass surface quality and $\mathrm{CO}_{2}$ content in beer on foam decay was investigated using our experimental method. The effect of beer glass surface quality on foam decay was experimentally investigated for: i) cold \& clean glass surface, ii) warm \& clean glass surface, iii) cold \& greasy glass surface, and iv) cold \& dusty glass surface. The fastest foam decay was observed for greasy glass surface. It was found that increasing $\mathrm{CO}_{2}$ content in beer: i) the liquid content in the foam decreases, and ii) the foam breaks down faster. The foam decay and growth kinetics of foam-liquid interface were statistically treated using own models.
\end{abstract}

\section{Introduction}

The quality of beer foam (volume, structure, stability, colour etc.) is a determining factor in the appearance of a good beer, especially for pilsner style beers. The pilsner style beers (i,e. beers produced by bottom-fermenting yeast) form large volume of dense and stable foam which clings on glass surface [1]. The foam of pilsner style beer should be stable approx. 200 seconds [2].

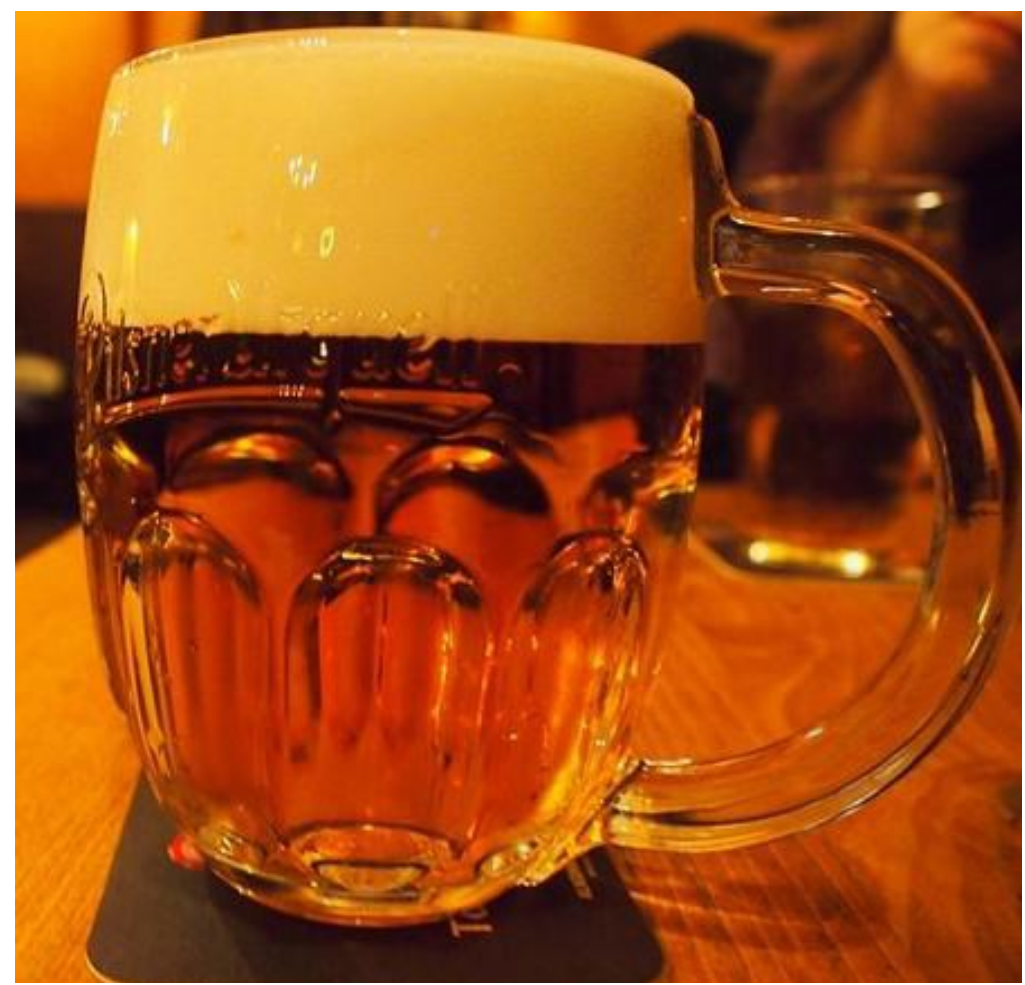

Fig. 1. Perfectly draught beer (Pilsner Urquell tank beer, restaurant Konvikt, Prague).
The perfectly draught beer is presented in Fig. 1. The formed foam has creamy appearance and protects beer against oxidation. The formed foam bubbles are small as possible. The absence of bubbles on glass surface signalizes the glass cleanliness. On the perfectly clean and cold glass the foam clings and forms circles on the glass surface (Fig. 2).

\footnotetext{
* Corresponding author: Radek.Sulc@,fs.cvut.cz
} 
The beer foam stability is usually determined using device of NIBEM [3]. The beer is filled straight from the bottle or can into the measuring vessel which imitates the pouring of beer. The method measures the time period of drop of foam- beer interface at three different heights after 10, 20 and $30 \mathrm{~mm}$. The measurement starts once the foam-beer interface drops for $10 \mathrm{~mm}$ under the edge of the cuvette.

Šrogl and Klasova [4] tested own method for foam stability testing. They foamed beer in laboratory mixer and then they measured time required for returning foam back into liquid. Šavel and Brož [5] summarized the principles and methods of measurement of beer foaming power including kinetic equations describing foam disintegration. Novak et al. [6] foamed beer in bubbled column by defined gas flowrate. The steady foam height in column was determined. In this state rate of foam forming equals to rate of foam decomposition.

Šavel [7] tested two models of the beer foam decomposition based on kinetics of $1^{\text {st }}$ order of isolated (foam $\rightarrow$ beer) and serial reaction (foam $\rightarrow$ beer in foam $\rightarrow$ beer). The foam decomposition was investigated in a cylindrical vessel with the diameter of $55 \mathrm{~mm}$ and the height of $130 \mathrm{~mm}$. The beer presented in the cylinder was foamed using the beer outflow from bottle or by the injection of defoamed beer. The second model was found to be better comparing with the first model that described only a part of the foam decomposition curve.

The experimental error of foam decay measurement using standard methods can reach up to $20 \%$ depending on the experimenter's experience. In our point of view the short decay time due to lower initial foam height is responsible for higher error rate of measuring methods.

The aim of this contribution is: i) to test own simple method for stability testing of beer foam without expensive measuring device, ii) to investigate the effect of beer glass surface quality and $\mathrm{CO}_{2}$ content in beer on foam decay and foam-liquid interface. The foam decay and growth kinetics of foam-liquid interface were statistically treated using own models.

\section{Theoretical background}

\subsection{Foam decay model}

The time dependence of dimensionless foam height $h_{F}{ }^{*}$ was described by S-curve as follows [8]:

$$
h_{F}^{*}\left(t_{F}\right)=\frac{1}{1+\exp \left(a_{0}+a_{1} \cdot t_{F}\right)}
$$

where: $a_{0}(-), a_{1}\left(\mathrm{~min}^{-1}\right)$ are parameters, $t_{F}(\mathrm{~min})$ is the time and dimensionless foam height $h_{F}{ }^{*}$ at time $t_{F}$ is defined as follows:

$$
h_{F}^{*}\left(t_{F}\right)=\frac{h_{F}\left(t_{F}\right)-h_{F f i n}}{h_{F 0}\left(t_{F 0}\right)-h_{F f i n}}
$$

where $h_{F 0}\left(t_{F 0}\right)$ is the foam height in the initial state, $h_{F f i n}$ is the foam height in the final state, and $h_{F}\left(t_{F}\right)$ is the foam height at time $t_{F}$. The S-curve form given by Eq. (1) can be transformed as follows:

$$
h_{F}^{*}\left(t_{F}\right)=\frac{1}{1+\exp \left(\ln \left(45^{2} / 55^{2}\right) \cdot \frac{\left(t_{F}-t_{F 0.5}\right)}{\left(t_{F 0.55}-t_{F 0.45}\right)}\right)}
$$

where $t_{F} 0.5(\mathrm{~min})$ is the time when the dimensionless foam height reaches $50 \%,\left(t_{F 0.55}-t_{F 0.45}\right)(\mathrm{min})$ is time difference from $45 \%$ to $55 \%$ of dimensionless foam height. Near the $50 \%$ of dimensionless foam height the curve is linear, thus we can estimate foam decay rate $v_{F}$ 0.50 in this point as follows:

$$
v_{F 0.5} \approx \frac{\Delta h_{F}^{*}}{\Delta t_{F}}=\frac{0.55-0.45}{t_{F 0.55}-t_{F 0.45}}
$$

where $t_{F 0.55}$ and $t_{F 0.45}$ are the times when the dimensionless foam height reaches $55 \%$ and $45 \%$, respectively. Combining Eqs. (3) and (4) the final formula describing the foam decay is obtained as follows:

$$
h_{F}^{*}\left(t_{F}\right)=\frac{1}{1+\exp \left(10 \cdot \ln \left(45^{2} / 55^{2}\right) \cdot v_{F 0.5} \cdot\left(t_{F}-t_{F 0.5}\right)\right)}
$$

\subsection{Growth model of foam-liquid interface}

The time dependence of liquid height is usually described [7] by kinetics of $1^{\text {st }}$ order in final form as follows:

$$
h_{L}^{*}\left(t_{L}\right)=1-\exp \left(-t / t_{\text {Lalt }}\right)
$$

where: $t_{\text {Lalt }}(\mathrm{min})$ is the average lifetime, $t_{L}(\mathrm{~min})$ is the time and dimensionless liquid height $h_{L}{ }^{*}$ at time $t_{L}$ is defined as follows:

$$
h_{L}^{*}\left(t_{L}\right)=\frac{h_{L}\left(t_{L}\right)-h_{L 0}\left(t_{L 0}\right)}{h_{L f i n}-h_{L 0}\left(t_{L 0}\right)}
$$

where $h_{L 0}\left(t_{L 0}\right)$ is the liquid height in the initial state, $h_{L f i n}$ is the liquid height in the final state, and $h_{L}\left(t_{L}\right)$ is the liquid height at time $t_{L}$. The parameter $t_{L}$ alt represents the time in which $63.2 \%$ of dimensionless liquid height is reached.

We found that model given by Eq. (6) is unsatisfactory at the beginning of liquid level formation. The delay of liquid level formation was observed in this period. Therefore, the model given by Eq. (6) was modified taking this effect into account as follows:

$$
\begin{gathered}
h_{L}^{*}\left(t_{L}\right)=1-\left(1-\tau_{L} / t_{\text {Lalt }}\right)^{-1} \times \\
\times\left(\exp \left(-t / t_{\text {Lalt }}\right)-\left(\tau_{L} / t_{\text {Lalt }}\right) \cdot \exp \left(-t / \tau_{L}\right)\right)
\end{gathered}
$$

where $\tau_{L}$ is the time delay. 
The measured properties are shown in Fig. 3.
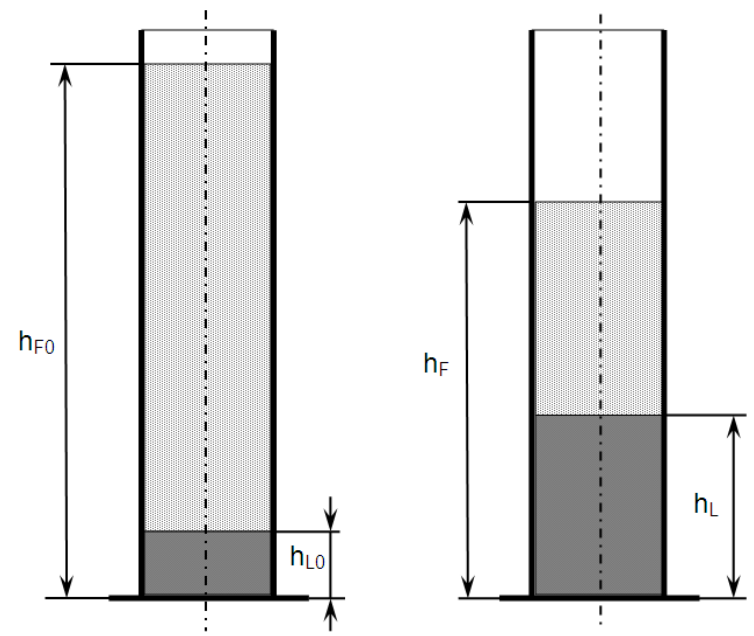

Fig. 3. Measured properties.

\section{Experimental}

The experimental procedure of our method occurs in following steps: i) Filling of glass cylinder of height of $190 \mathrm{~mm}$ by beer foam, ii) Visual observation of foam decay in time. We assume that the uncertainty should be decreased increasing the initial foam height.

The beer foam was formed by special way of beer serving. In this case, the beer foam outflows only from beer tap (in Czech slang this serving style is called "mliko").

\subsection{Effect of beer glass surface quality}

The cold \& clean glass surface was prepared by the following procedure: i) washing with water and degreasing agent, ii) rinsing with tap water, and iii) cooling in the refrigerator to temperature of $7^{\circ} \mathrm{C}$. The warm \& clean glass surface was prepared by heating of clean glass to temperature of $37^{\circ} \mathrm{C}$. This temperature corresponds to the typical temperature of glass from dishwasher. The cold \& greasy glass surface was prepared by laying of a thin layer of pork lard on cold \& clean glass surface. The greasy glass corresponds to wrongly washed glass. The cold \& dusty glass surface was prepared by laying of a dust on cold \& clean glass surface. The $10^{\circ}$ Gambrinus beer was used for experiments.

\subsection{Effect of beer $\mathrm{CO}_{2}$ content}

The $12^{\circ}$ unfiltered Hubertus lager produced by brewery Kácov was used for experiments. The beer was stored in beer barrel at $6^{\circ} \mathrm{C}$. The $\mathrm{CO}_{2}$ content was increased gradually from 4.6 to $9.7 \mathrm{~g} / \mathrm{L}$ in the barrel by means of gaseous $\mathrm{CO}_{2}$ atmosphere under liquid. The initial value of $\mathrm{CO}_{2}$ content of $4.6 \mathrm{~g} / \mathrm{L}$ lies in the range of $\mathrm{CO}_{2}$ content (4-5 g/L) typical for pilsner style beer.

\section{Data analysis}

\subsection{Effect of beer glass surface quality}

\subsubsection{Foam decay}

The evaluated model parameters for various quality of glass surface are presented in Table 1. The comparison of experimental data and predicted foam decomposition is presented in Fig. 4 for tested surfaces. The agreement of model curve and experimental data is relatively very well for all tested surfaces. Some discrepancies can be found at the initial and final state of foam decomposition.

As it follows from Fig. 4, the foam decay depends on glass surface quality. As expected, the longest time for the total foam decomposition was observed for clean \& cold glass (12 minutes). The shortest time was observed for cold \& greasy glass (8 minutes). As it follows from Fig. 4, the foam height in the final state is the same for all tested types of glass surface. This fact signalizes that the liquid content present in foam was the same for all tests. For illustration, the foam quality is presented in Fig. 5 for cold \& dusty glass surface and cold \& clean glass surface.

Table 1. Foam decay - effect of beer glass surface quality: S-curve parameters.

\begin{tabular}{|c|c|c|c|c|c|}
\hline Beer glass surface quality & $\begin{array}{c}\boldsymbol{t}_{F} \mathbf{0 . 5} \\
(\mathbf{m i n})\end{array}$ & $\begin{array}{c}\boldsymbol{v}_{F 0.5} \\
\left(\mathbf{m i n}^{-1}\right)\end{array}$ & $\begin{array}{c}\boldsymbol{h}_{\boldsymbol{F} 0} \\
(\mathbf{m m})\end{array}$ & $\begin{array}{c}\boldsymbol{h}_{F \text { fin }} \\
(\mathbf{m m})\end{array}$ & $\begin{array}{c}\mathbf{R} \\
(-)\end{array}$ \\
\hline cold \& clean glass surface & 6.3 & -0.143 & 190 & 87.5 & 0.994 \\
\hline warm \& clean glass surface & 5.76 & -0.202 & 190 & 87 & 0.996 \\
\hline cold \& greasy glass surface & 5.67 & -0.184 & 190 & 88 & 0.993 \\
\hline cold \& dusty glass surface & 4.84 & -0.200 & 190 & 88 & 0.975 \\
\hline
\end{tabular}




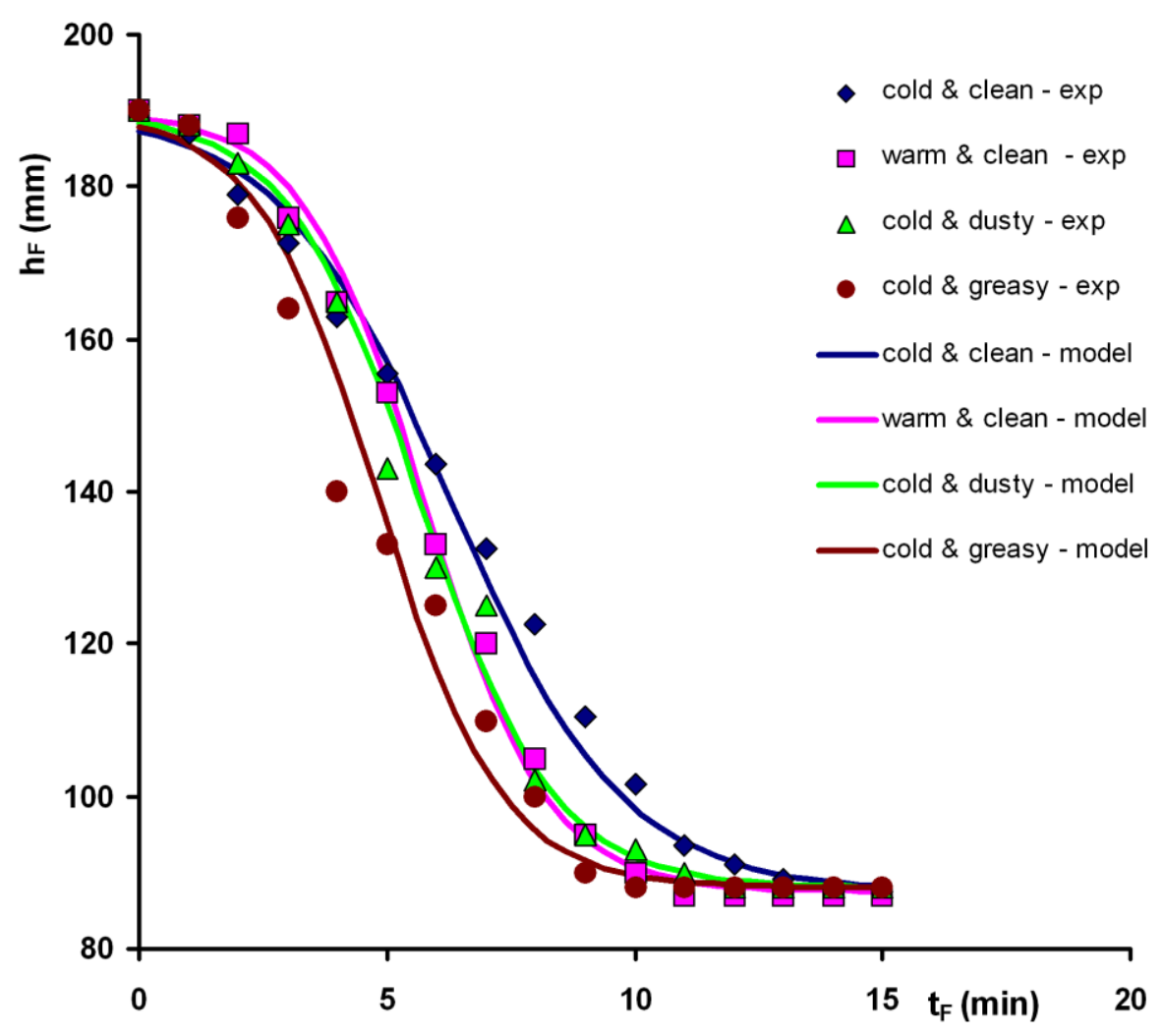

Fig. 4. Foam decay - effect of beer glass surface quality.

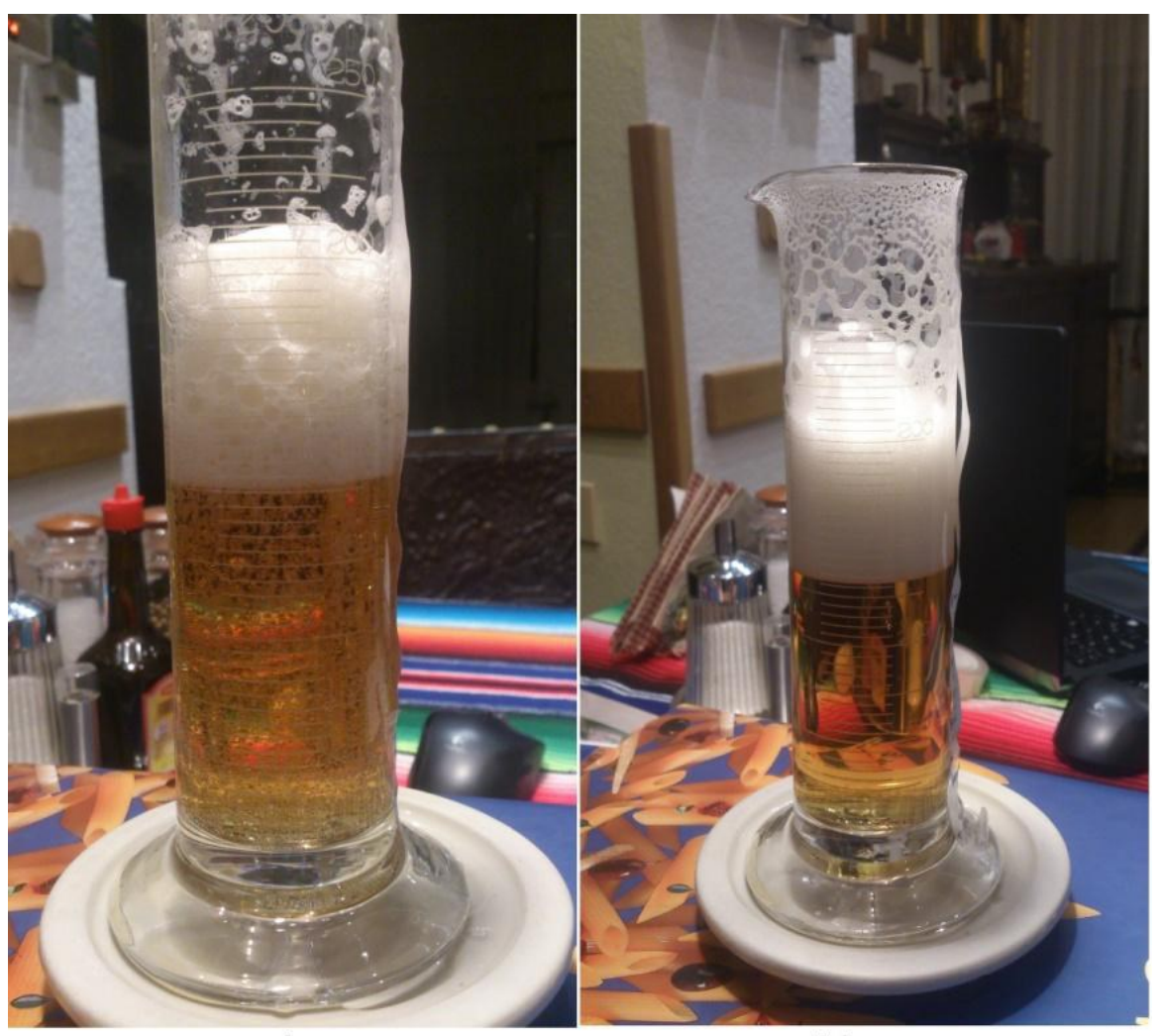

a)

a) cold \& dusty glass surface

The thin foam contains large bubbles.

The glass surface is covered by small bubbles.

\section{b)}

b) cold \& clean glass surface

The dense foam contains small bubbles.

The glass surface clean without captured bubbles. 
Table 2. Liquid formation - effect of beer glass surface quality.

\begin{tabular}{|c|c|c|c|c|c|c|c|}
\hline Beer glass surface quality & $\begin{array}{c}\tau_{L} \\
(\min )\end{array}$ & $\begin{array}{c}t_{L} \text { alt } \\
(\mathrm{min})\end{array}$ & $\begin{array}{c}\tau_{L} / t_{L} \text { alt } \\
(-)\end{array}$ & $\begin{array}{c}h_{L O} \\
(\mathrm{~mm})\end{array}$ & $\begin{array}{l}h_{L f i n} \\
(\mathrm{~mm})\end{array}$ & $\begin{array}{c}h_{L \text { fin }}-h_{L O} \\
(\mathrm{~mm})\end{array}$ & $\begin{array}{l}R \\
(-)\end{array}$ \\
\hline cold \& clean glass surface & 0.09 & 3.35 & 0.03 & 16 & 93 & 77 & 0.999 \\
\hline warm \& clean glass surface & 1.19 & 2.13 & 0.56 & 14 & 81 & 67 & 0.999 \\
\hline cold \& greasy glass surface & 1.06 & 1.44 & 0.74 & 18 & 82 & 64 & 0.997 \\
\hline cold \& dusty glass surface & 1.2 & 1.29 & 0.93 & 15 & 81.5 & 66.5 & 0.997 \\
\hline
\end{tabular}

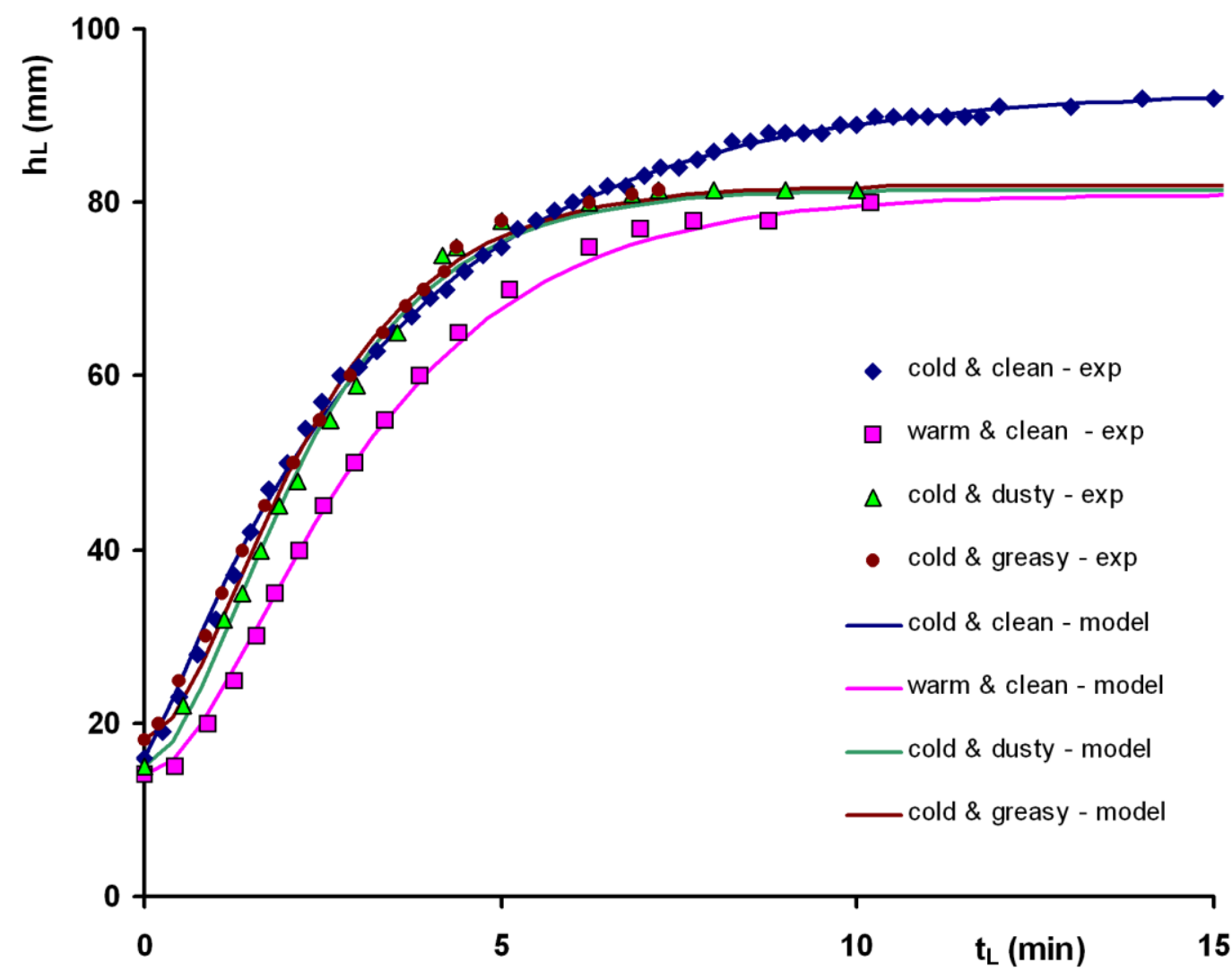

Fig. 6. Liquid formation - effect of beer glass surface quality.

\subsubsection{Liquid formation}

The evaluated model parameters for various quality of glass surface are presented in Table 2. The comparison of experimental data and liquid height growth predicted by Eq. (8) is presented for tested surfaces in Fig. 6. The agreement of model and experimental data is very well for all tested surfaces.

As it follows from Fig. 6, the liquid formation depends on glass surface quality. As expected, the longest average lifetime and the highest liquid height in the final state were observed for clean \& cold glass ( 3.35 minutes and 77 milimeters). As it follows from Fig. 6, the liquid heights in the final state are different for tested types of glass surface. This fact signalizes that the liquid content present in foam was not the same. The lowest liquid content was observed for cold $\&$ greasy glass. The significant effect of glass surface was observed for time delay $\tau_{L}$. The value close to zero was found for cold \& clean glass surface. For other surfaces the values greater than 1 minute were evaluated. 


\subsection{Effect of beer $\mathrm{CO}_{2}$ content}

\subsubsection{Foam decay}

The evaluated model parameters for various beer $\mathrm{CO}_{2}$ content are presented in Table 3. The comparison of experimental data and predicted foam decomposition is presented in Fig. 7. The agreement of model curve and experimental data is relatively very well for all tested $\mathrm{CO}_{2}$ contents. Some discrepancies can be found at the initial and final state of foam decomposition.

Table 3. Foam decay - effect of beer $\mathrm{CO}_{2}$ content: S-curve parameters.

\begin{tabular}{|c|c|c|c|c|c|c|}
\hline $\begin{array}{c}\mathbf{c}_{\mathbf{C O} 2} \\
(\mathrm{~g} / \mathbf{L})\end{array}$ & $\begin{array}{c}\boldsymbol{t}_{F} \mathbf{0 . 5} \\
(\mathbf{m i n})\end{array}$ & $\begin{array}{c}\boldsymbol{v}_{F 0.5} \\
\left(\mathbf{m i n}^{-1}\right)\end{array}$ & $\begin{array}{c}\boldsymbol{h}_{F 0} \\
(\mathbf{m m})\end{array}$ & $\begin{array}{c}\boldsymbol{h}_{F f i n} \\
(\mathbf{m m})\end{array}$ & $\begin{array}{c}\boldsymbol{h}_{F f i n} / \boldsymbol{h}_{F 0} \\
(-)\end{array}$ & $\begin{array}{c}\mathbf{R} \\
(-)\end{array}$ \\
\hline 4.6 & 7.20 & -0.111 & 190 & 80 & 0.421 & 0.996 \\
\hline 6.2 & 7.80 & -0.114 & 190 & 66 & 0.347 & 0.997 \\
\hline 7.9 & 7.83 & -0.086 & 190 & 55 & 0.289 & 0.994 \\
\hline 8.7 & 6.91 & -0.119 & 190 & 52 & 0.274 & 0.995 \\
\hline 9.7 & 6.77 & -0.108 & 190 & 46 & 0.242 & 0.994 \\
\hline
\end{tabular}

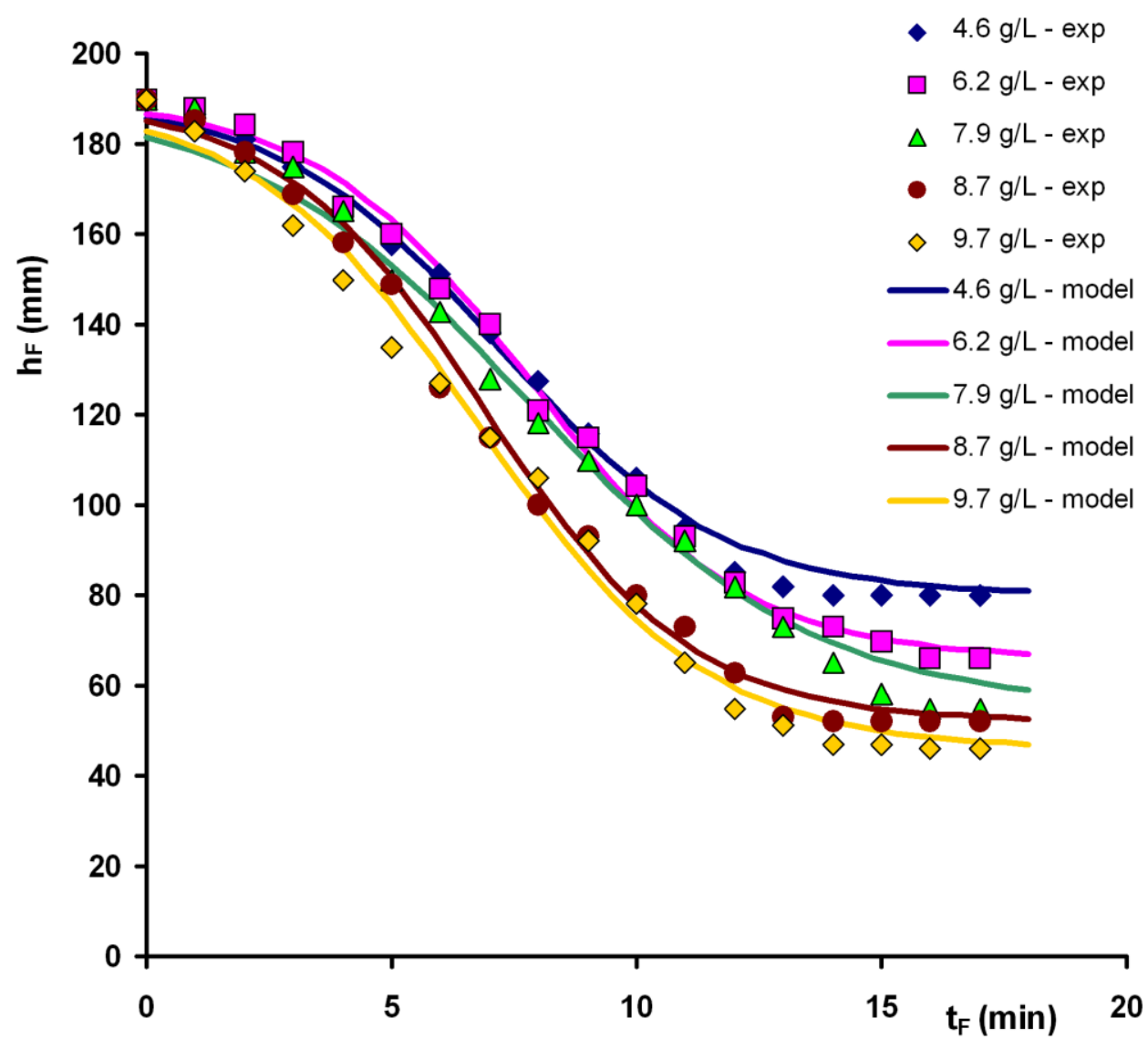

Fig. 7. Foam decay - effect of beer $\mathrm{CO}_{2}$ content. 
Increasing $\mathrm{CO}_{2}$ content the foam is decomposed faster. The decreasing foam height in the final state for higher $\mathrm{CO}_{2}$ content signalizes that the higher $\mathrm{CO}_{2}$ content the lower liquid content is present in beer foam. The following dimensional relations were found for parameters $t_{F 0.5}, v_{F 0.5}$ and $h_{F f i n} / h_{F 0}$ :

$$
\begin{gathered}
t_{F 0.5}=-0.1433 \cdot c_{C O 2}^{2}+1.9711 \cdot c_{C O 2}+1.1457 \\
(\mathrm{R}=0.995) \\
v_{F 0.5} \approx-0.109 \\
h_{F f i n} / h_{F 0}=1.276 \cdot c_{C O 2}^{-0.72} \quad(\mathrm{R}=0.997)
\end{gathered}
$$

where $t_{F 0.5}(\mathrm{~min}), v_{F 0.5}(\min -1)$ and $c_{C O 2}(\mathrm{~g} / \mathrm{L})$. The effect of $\mathrm{CO}_{2}$ content on foam decay rate was found to be negligible. For illustration, the obtained relations are graphically shown in Figs. 8, 9 and 10.

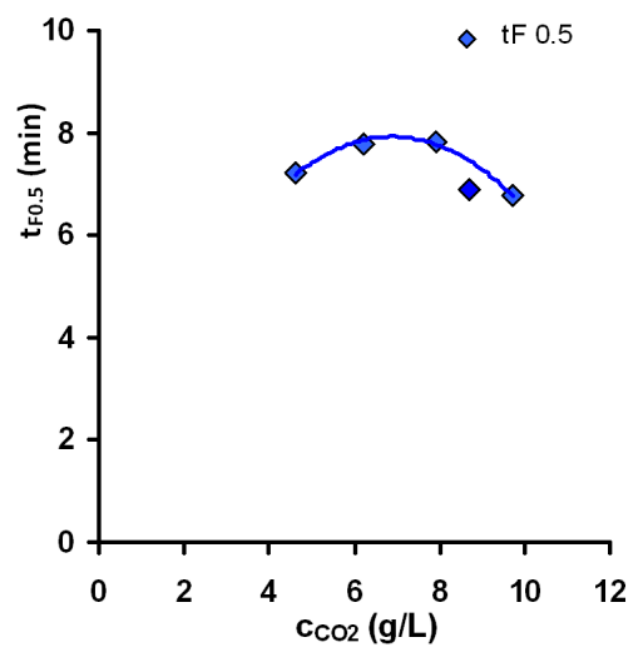

Fig. 8. Foam decay - effect of $\mathrm{CO}_{2}$ content: parameter $t_{F 0.5}$.

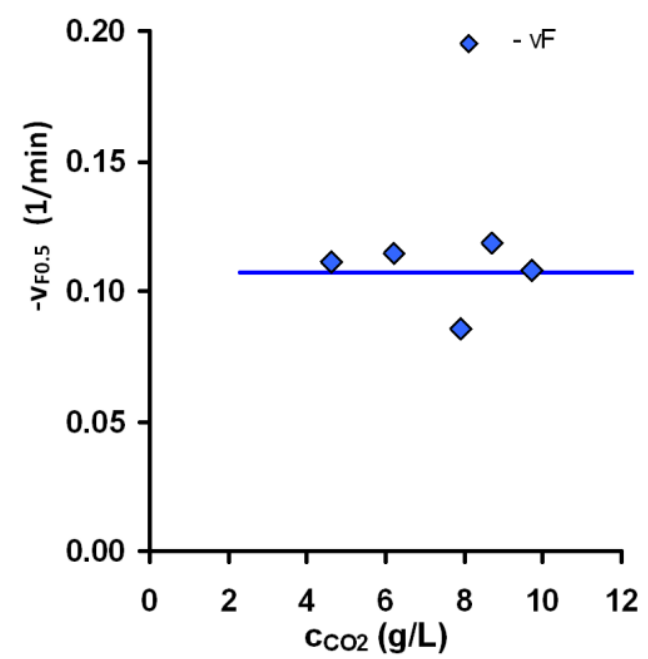

Fig. 9. Foam decay - effect of $\mathrm{CO}_{2}$ content: parameter $v_{F 0.5}$.

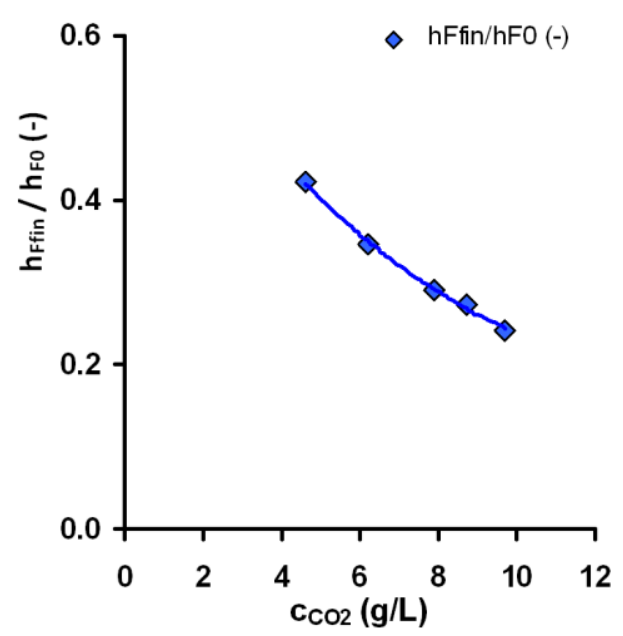

Fig. 10. Foam decay - effect of $\mathrm{CO}_{2}$ content: $h_{F f i n} / h_{F 0}$ ratio.

\subsubsection{Liquid formation}

The evaluated model parameters for various beer $\mathrm{CO}_{2}$ content are presented in Table 4. The comparison of experimental data and liquid height growth predicted by Eq. (8) is presented for tested $\mathrm{CO}_{2}$ contents in Fig. 11. The agreement of model and experimental data is relatively very well for all tested $\mathrm{CO}_{2}$ contents.

The time delay $\tau_{L}$ and average lifetime $t_{L}$ alt decrease with increasing $\mathrm{CO}_{2}$ content in the beer. The effect of $\mathrm{CO}_{2}$ content is clearly visible for parameters $\tau_{L}, \tau_{L} / t_{L}$ alt ratio and $h_{\text {Lfin. }}$. For $\mathrm{CO}_{2}$ content greater then $6.2 \mathrm{~g} / \mathrm{L}$ the liquid is released from foam immediately after foaming.

The following dimensional relations were found for parameters $\tau_{L}, t_{L \text { alt }}$ and $h_{L f i n}$ :

$$
\begin{aligned}
& \tau_{L}=12.047 \cdot c_{C O 2}^{-1.2} \quad(\mathrm{R}=0.996) \\
& t_{\text {Lalt }}=4.318 \cdot c_{\mathrm{CO} 2}^{-0.25} \quad(\mathrm{R}=0.84) \\
& \tau_{L} / t_{\text {Lalt }}=2.791 \cdot c_{\mathrm{CO2}}^{-0.95} \quad(\mathrm{R}=0.969) \\
& h_{L f i n}=195 \cdot c_{C O 2}^{-0.6} \quad(\mathrm{R}=0.982)
\end{aligned}
$$

where $\tau_{L}(\mathrm{~min}), t_{L \text { alt }}(\mathrm{min}), h_{L f i n}(\mathrm{~mm})$ and $c_{\mathrm{CO} 2}(\mathrm{~g} / \mathrm{L})$. For illustration, the obtained relations are graphically shown in Figs. 12, 13 and 14. 
Table 4. Liquid formation - effect of beer $\mathrm{CO}_{2}$ content.

\begin{tabular}{|c|c|c|c|c|c|c|c|}
\hline $\begin{array}{l}\mathrm{c}_{\mathrm{CO} 2} \\
(\mathrm{~g} / \mathrm{L})\end{array}$ & $\begin{array}{c}\tau_{L} \\
(\min )\end{array}$ & $\begin{array}{c}t_{L} \text { alt } \\
(\min )\end{array}$ & $\begin{array}{c}\tau_{L} / t_{L} \text { alt } \\
(-)\end{array}$ & $\begin{array}{c}h_{L O} \\
(\mathrm{~mm})\end{array}$ & $\begin{array}{l}h_{L f i n} \\
(\mathrm{~mm})\end{array}$ & $\begin{array}{c}h_{L f i n}-h_{L 0} \\
(\mathrm{~mm})\end{array}$ & $\begin{array}{l}\mathbf{R} \\
(-)\end{array}$ \\
\hline 4.6 & 1.97 & 2.92 & 0.675 & 0 & 75 & 75 & 0.998 \\
\hline 6.2 & 1.29 & 2.90 & 0.445 & 5 & 61.5 & 56.5 & 0.999 \\
\hline 7.9 & 1.02 & 2.37 & 0.430 & 4 & 54 & 50 & 0.997 \\
\hline 8.7 & 0.88 & 2.60 & 0.338 & 6 & 52 & 46 & 0.999 \\
\hline 9.7 & 0.80 & 2.44 & 0.330 & 5 & 46 & 41 & 0.997 \\
\hline
\end{tabular}

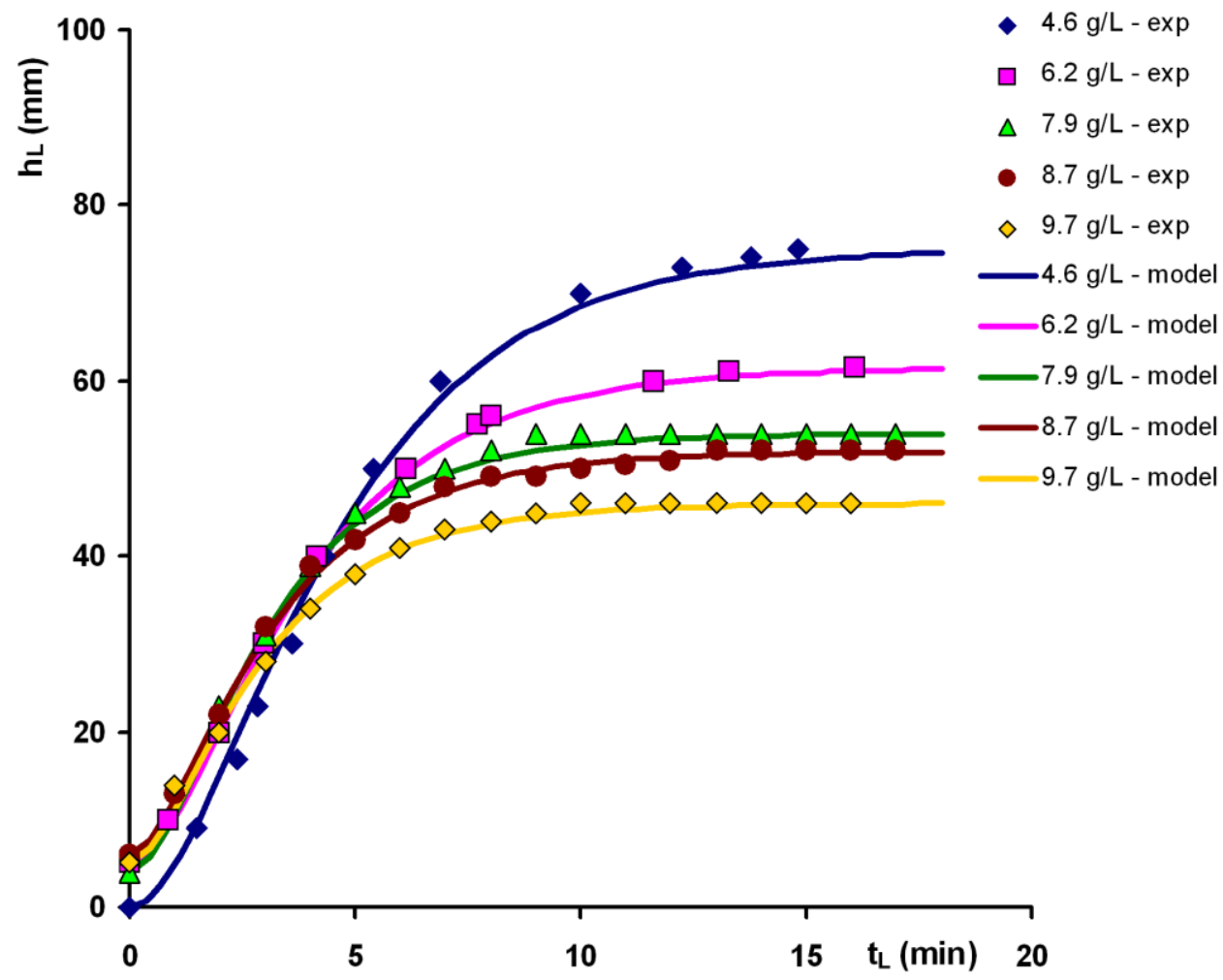

Fig. 11. Liquid formation - effect of $\mathrm{CO}_{2}$ content. 


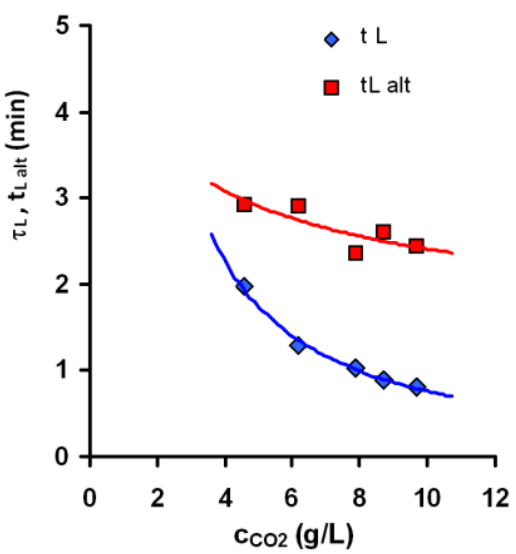

Fig. 12. Liquid formation - effect of $\mathrm{CO}_{2}$ content: parameters $\tau_{L}$ and $t_{L}$ alt .

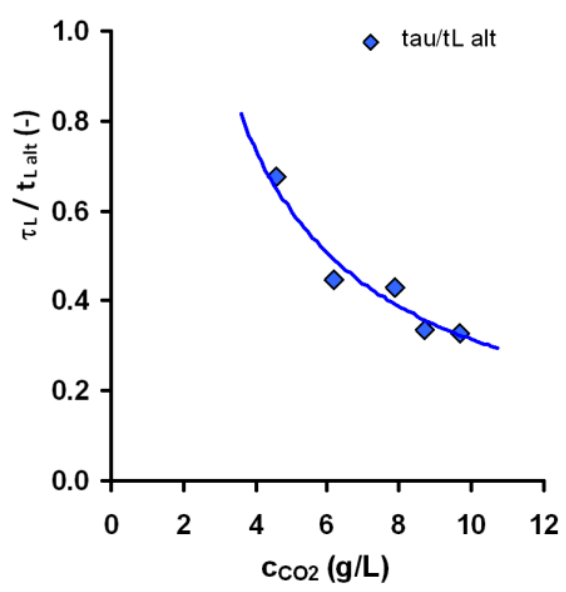

Fig. 13. Liquid formation - effect of $\mathrm{CO}_{2}$ content: $\tau_{L} / t_{L}$ alt ratio.

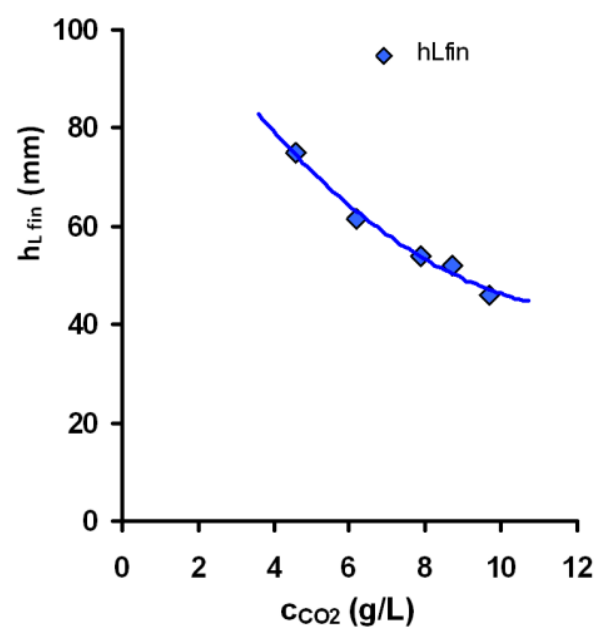

Fig. 14. Liquid formation - effect of $\mathrm{CO}_{2}$ content: parameter $h_{L}$ fin .

\section{Conclusions}

The effect of beer glass surface quality and $\mathrm{CO}_{2}$ content in beer on foam decay was investigated using our experimental method.
The effect of beer glass surface quality on foam decay was experimentally investigated for: i) cold \& clean glass surface, ii) warm \& clean glass surface, iii) cold \& greasy glass surface, and iv) cold \& dusty glass surface. The fastest foam decay was observed for greasy glass surface.

Increasing beer $\mathrm{CO}_{2}$ content the foam decomposition is faster. It was found that increasing $\mathrm{CO}_{2}$ content in beer: i) the liquid content in the foam decreases, and ii) the foam breaks down faster. The foam decay and growth kinetics of foam-liquid interface were statistically treated using own models.

This work was supported by grant No. SGS16/149/OHK2/2T/ 12 of the Grant Agency of the Czech Technical University in Prague and RVO: 68407700 MSMT ČR.

\section{Symbols}

$c_{\mathrm{CO} 2}$ mass concentration of $\mathrm{CO}_{2}$ dissolved in beer, $\mathrm{g} / \mathrm{L}$

$h_{F} \quad$ foam height, $\mathrm{mm}$

$h_{F}{ }^{*} \quad$ dimensionless foam height, -

$h_{F 0}$ foam height in the initial state, $\mathrm{mm}$

$h_{\text {Ffin }}$ foam height in the final state, $\mathrm{mm}$

$h_{L} \quad$ liquid height, $\mathrm{mm}$

$h_{L}{ }^{*} \quad$ dimensionless liquid height,-

$h_{L 0} \quad$ liquid height in the initial state, $\mathrm{mm}$

$h_{\text {Lfin }}$ liquid height in the final state, $\mathrm{mm}$

$\mathrm{R}$ correlation index, -

$t_{F} \quad$ time of foam decomposition, min

$t_{F 0.5}$ time when the dimensionless foam height reaches $50 \%$, min

$t_{L} \quad$ time of liquid formation, min

$t_{\text {Lalt }}$ average lifetime, min

$v_{F 0.50}$ - foam decay rate, min $^{-1}$

\section{Greek symbols}

$\tau_{L}$ time delay, min

\section{References}

1. G. Basařova, Czech beer (in Czech) (NUGA, Prague, 2009)

2. M. Baszcyňski, T. Brányik, Struktura pivní pěny, In: Proceedings of Conference "Kvasná chemie a bioinženýrství 2010” (Prague, 2010)

3. W.J. Klopper, H.A. Vermeire, Brauwissenschaft 30, 276 (1977)

4. J. Šrogl, V. Klasová, Kvasný průmysl 22, 28 (1976)

5. J. Šavel, A. Brož, Kvasný průmysl 52, 314 (2006)

6. P. Novák, M. Baszcyňski, T. Brányik, M.C. Růžička, Vliv vybraných fyzikálně-chemických vlastností piva na stabilitu pěny, In: Proceedings of Conference "Kvasná chemie a bioinženýrství 2010" (Prague, 2010)

7. J. Šavel, Kvasný průmysl 32, 76 (1986)

8. L.J. Reed, J. Berkson, J. Phys. Chem. 33, 760 (1929) 